\title{
Comprehensive approach to the restoration of historical and cultural monuments (example of the mansion of A. A. Polovtsov)
}

\author{
Petr Shchedrin ${ }^{1, *}$ \\ ${ }^{1}$ Saint-Petersburg State University of Architecture and Civil Engineering, 190005, St. Petersburg, \\ Russia
}

\begin{abstract}
The article deals with the problems of restoration design and study of cultural heritage objects that have a long history of existence and operation since the first half of the 19th century. The main aspects faced by researchers of monuments in our time are listed. The list of problems that designers face when studying such objects in St. Petersburg is given. A small dive into the technology of historical development for 250-300 years in St. Petersburg is made. The features of historic masonry and reinforced masonry structures are discussed. In particular, the problems of the state of brickwork walls of cultural heritage monuments of the early 19th century are listed. As a result, it can be stated that the technical and technological difficulties of restoration and the most problematic objects in the design were left to the current generation. We can also say that the current community of restoration designers, to a greater extent, does not take into account many factors that affect the integrity and load-bearing capacity of masonry historical walls. Using the example of a cultural heritage object the building of the mansion of A. A. Polovtsov, the stages of design of restoration work and analysis of the result obtained and forced corrections after detailed restoration implementation in the structure during its restoration and conservation are given.
\end{abstract}

\section{Introduction}

Analysis of the practice of restoration design and protection of cultural heritage. Engineering aspects of restoration of structures in the interior using the example of one interior of the building of the mansion of A.A. Polovtsov ("House of the Architect") located at the address: B. Morskaya street, 52, Saint Petersburg.

When creating a project for the restoration of interiors, there is a problem of a qualitative examination of the structures of architectural monuments in the presence of valuable finishes in the interiors, and, in particular, overhead wooden panels and stretched decorative fabrics, tapestries, as well as glued-laminated parquet.

What do researchers face when examining:

- decorative fabric must be removed to examine all the walls;

\footnotetext{
* Corresponding author: 3066475spb@mail.ru
} 
- parquet floors must also be opened, and this is another type of activity, different from design, which is called restoration. And most design firms licensed to develop restoration projects do not have a license to carry out restoration work themselves. And the cost of a one-time introduction to an architectural monument is also high.

On the other hand, customers, wanting to save money on design work, do not include the dismantling of decorative fabrics, panels and other valuable finishes for the quality inspection of building structures in the terms of reference. It limits the designers to the volume of the room itself, without going beyond the inner surface of the walls, thereby preventing the study of the wall structure and restricts itself in obtaining quality information on the property it owns.

\section{Methods}

In the presented work, we used a comprehensive multi-level research, which will represent various stages: preliminary acquaintance with the object, when the first visual study is made, performs measurements and familiarizes with the primary information contained in the documentation stored in the state bodies for the protection of monuments and in the most accessible literature, preliminary examination with the involvement of the future author of the restoration project. Based on the preliminary survey, the scope, composition and direction of further research work are determined.

\section{Results}

At this historical moment, restorers are faced with the accumulated problematic aspects of the technical condition of cultural heritage sites:

- long service life of monuments without repair;

- the venerable age of the monuments and their technical wear;

- a large volume of architectural monuments, which have not undergone major repairs or major restoration interventions, has a low margin of safety for structures by the formulas for calculating the bearing capacity according to Russian State Standard GOST [1-3], [9];

- many elements of supporting structures: foundations; walls; overlapping to a greater extent; and the other enclosing structures have some degree of destruction, which many restorers did not pay attention to before;

- for the most part, the so-called cosmetic restorations were made, without any special introduction in the design. More attention was paid to interior decoration than to the structures of the building itself, considering them secondary. Or thinking "that our grandfathers have built for centuries and there will be enough margin of safety for our century" [10];

- the lack of qualified designers-restorers in the 20th century. So, according to Mark Grigorievich Kolotov, SPA "Restavrator", the first designer appeared in 1985 at Savior on Blood;

- the cost of interior restoration is not comparable with the cost of repairing structures (all the amplifications are most often estimated by general construction, cheap, prices). Strengthening ceilings, walls and foundations are not as beneficial as restoration of interior decoration, especially from valuable objects of decorative and applied art. It was easier to repair the upper layer of parquet than to disassemble the entire floor and reinforce the floor beams;

- the pathological fear of the supervisory authorities for the protection of monuments to introduce into the structures, and even more so to disassemble them, also does not stimulate the desire of restorers to introduce into the structures and make their reinforcement; 
- the lack of desire to deal with problematic structures due to complex finishes that no one wants to open "in vain" without very obvious prerequisites - that is, without the occurrence of an Emergency condition;

- not developed historical information on the restructuring and changes in structures and their repairs. Archival information is not enough;

- the presence of poor measurements of the structures of the entire monument;

- poor full-scale photographic fixation and the absence of iconographic materials leads to incorrect conclusions about the state of the bearing capacity of structures and, as a result, the reluctance of global introductions into the monument;

- the lack of high-quality, knowledgeable analysts of historical structures, construction technologies and financial lack of demand by customers exacerbate the full study of monuments.

As a result, the technical and technological difficulties in restoration and the most problematic objects remained for the current generation of architects-restorers.

At the moment, the capabilities of restorers of the first quarter of the 21 st century differ from the 40-80s of the 20th century both in technical and material capacities (financing of facilities, the ability to purchase the necessary materials, simple and complex chemicals, auxiliary capabilities for instrumental and laboratory research), which should somewhat ease the conditions of restoration and please our generation of restorers.

Technology of historical development in St. Petersburg for 250-300 years:

- Many stone buildings that still remained have gone through their high-rise and floorto-floor growth from a single-storey building with a basement (early 18th century) to 3-6 storey building (20th century).

- It should be noted that the foundations of many high-rise buildings remained the same made for a one-story building. Short pile driving or stub system on which the old foundation rested.

- The brick walls of the first floor, often made of 2.0 bricks, did not provide adequate thermal insulation, and also bearing capacity with a superstructure of the second floor.

- After the building of superstructures, an uneven subsidence of historical buildings appeared with the appearance of cracks.

- The presence of cracks through each window opening over the entire height, the spread of walls and foundations. Add here a constant digging of trenches for laying communications and leaking water pipes and heating - washing out the foundations.

- Continuous improvement of the heating system of buildings led to constant cuts in the walls of new channels, often without laying old ones.

- Improving the ventilation system of buildings required cutting through the bearing walls of new channels.

- The appearance of water heating increased the heat pressure on the historical enclosing structures, which could not be taken into account in the bearing capacity of structures by former builders, and the current maintenance services did not take this into account too. As a result, there are heat losses through attic floors, walls and ceilings.

- Increased wall vibration due to heavy road vehicles passing on city roads. The appearance of vibrational cracks in building structures was noted back in the 1950s by the architect A.L. Rotach. [20]

Features of stone and reinforced historical structures: bricks of various configurations, stone, granite, limestone, sandstone, marble.

Before the revolution, there were about 70 brick factories around St. Petersburg. The brick manufacturing process was designed for two years: in the first year, clay was prepared on the ground, kneaded, and was frozen during winter. In the spring, it was kneaded again, molded, dried, and sent to the oven. Brick has advantages over other materials because it is 
both a supporting, heat-insulating and finishing material, and at the same time meets the requirements of fire safety, reliability and ease of construction.

Problems of the state of masonry walls:

- different sized old bricks;

- different brickwork and variety of bricks during the reconstruction of old buildings;

- masonry mortars of low grade, but calcareous, with high vapor permeability;

- masonry with empty seams;

- applied rows thickening the walls, but performed without binding;

- cracking of the brick body under load;

- the presence of furnace and ventilation channels cut through the walls, weakening the bearing capacity;

- communications (heating and electricity) laid through the walls cut them and weaken them.

- masonry of the kiln channels was carried out on clay mortar, and not on lime, which also reduces the bearing capacity of the walls.

\section{Discussion}

One of the premises of the first floor in the House of the Architect (St. Petersburg, B. Morskaya street, 52) is proposed for consideration as an example of the complexity of studying and designing the restoration of individual interior structures (Fig.1-9).

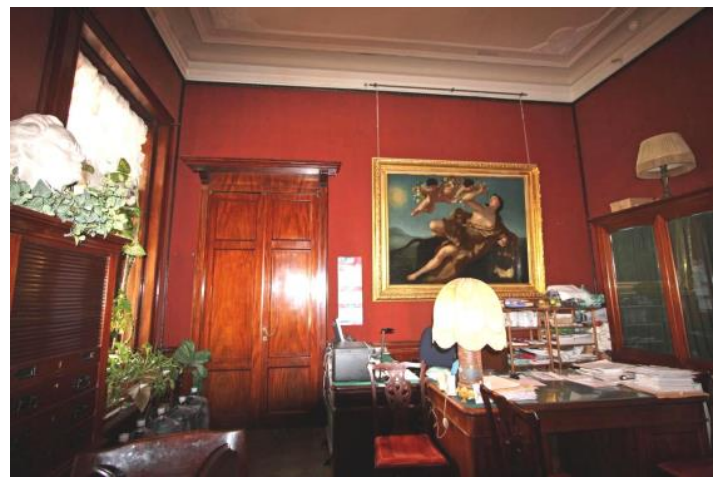

Fig. 1. General view. The studied room before restoration. Saturated with decorative fabrics and wood paneling on the walls.

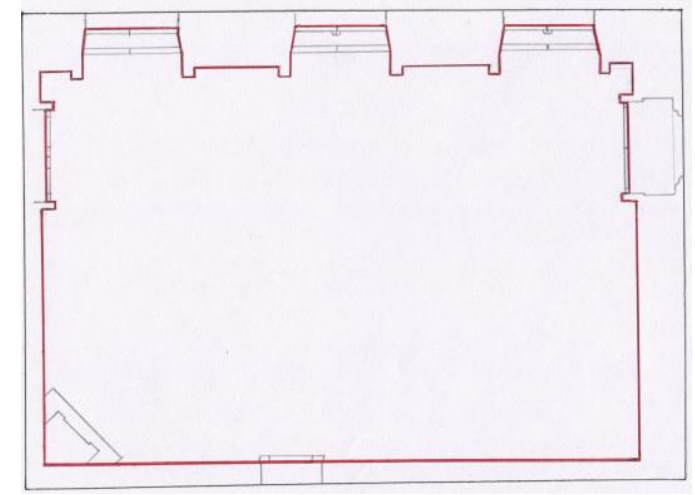

Fig. 2. Plan of the projected volume. 
The customer set a task to develop a project for the restoration of the interior of the premises of the former "Dressing room" without studying the wall structures. Previous historical study of the mansion made by A.A. Polovtsov generally described only the main milestones in the history of ownership and major restructuring of the building, but no more [11-14]. A practical description of the structures and their study is not currently compiled throughout the monument. For the most part, only leading architects and owners of this monument are described. [15-18].

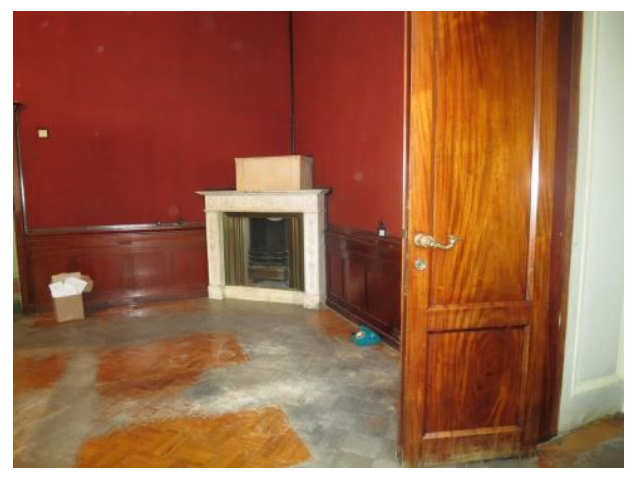

Fig. 3. General view after the removal of furniture. The walls are covered with decorative fabric. The lower part of the walls is decorated with panels. Floor - glued-laminated parquet.

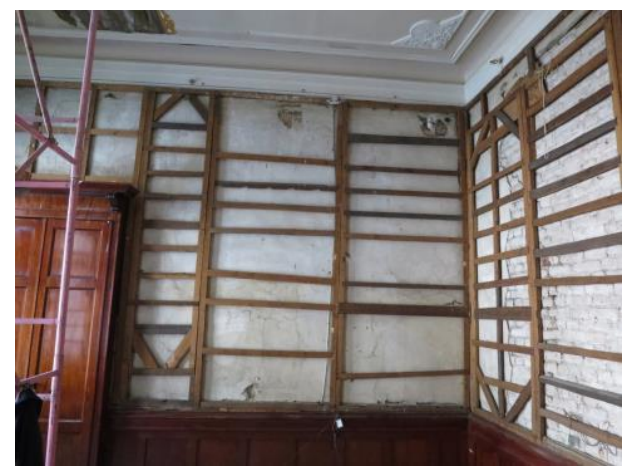

Fig. 4. View after dismantling decorative fabric. A wooden frame is visible. There are cracks in the masonry and crumbling plaster.

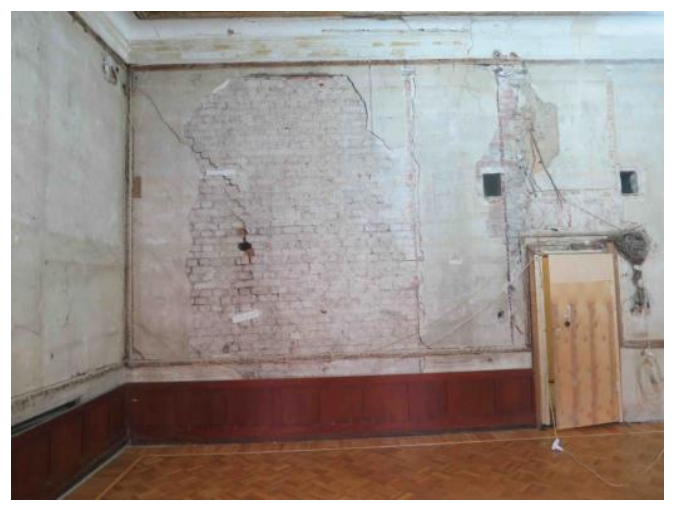

Fig. 5. View after dismantling the frame. The crack in the brick wall is clearly visible. 


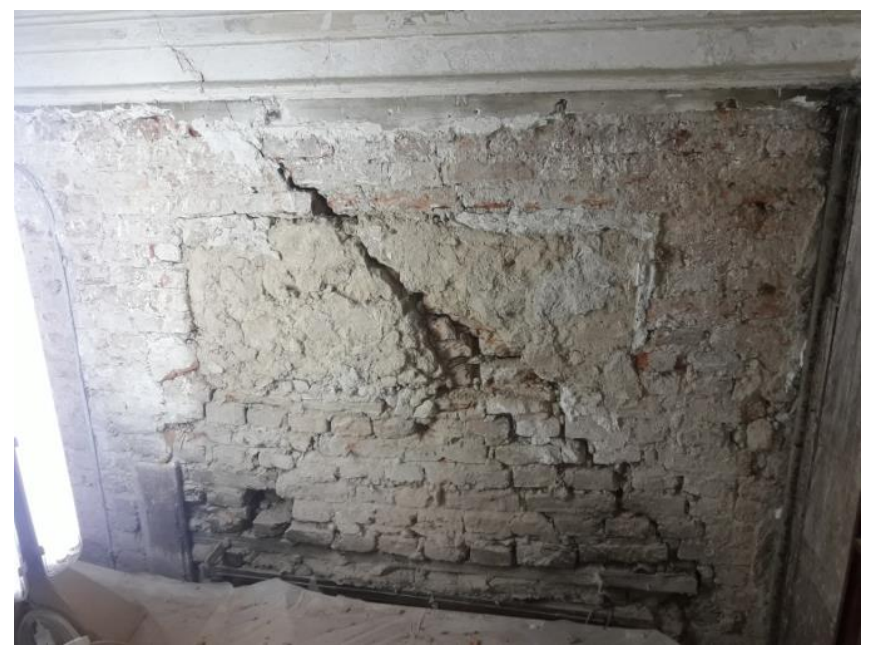

Fig. 6. View of the lintel of the doorway after removing the plaster. A structural crack and masonry destruction are visible. The wall sank and rested on the door filling.

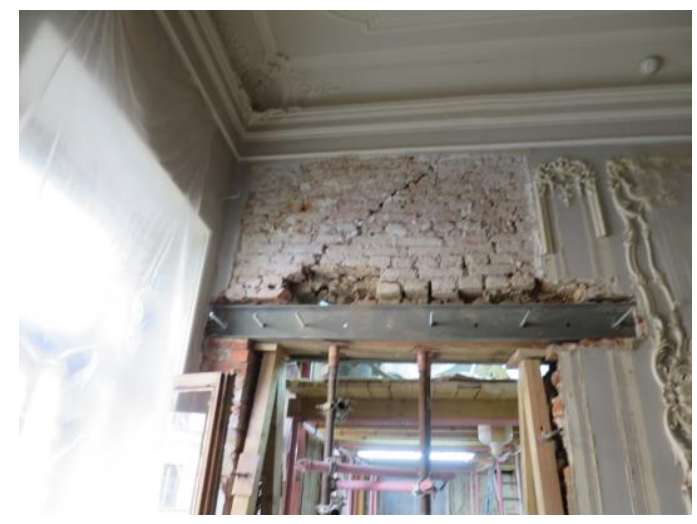

Fig. 7. View of the lintel during masonry reinforcement.

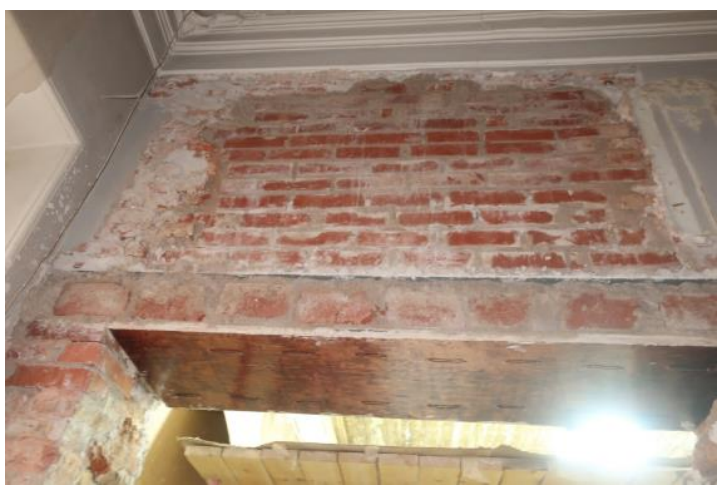

Fig. 8. Reinforcement of the lintel with the repair of brick. 


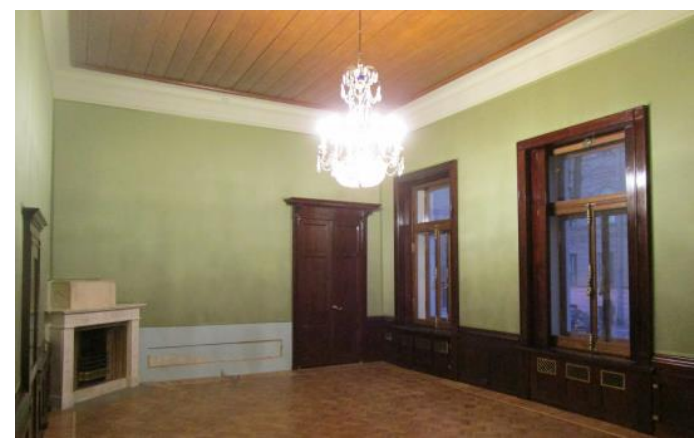

Fig. 9. View after restoration of the "Dressing room" interior.

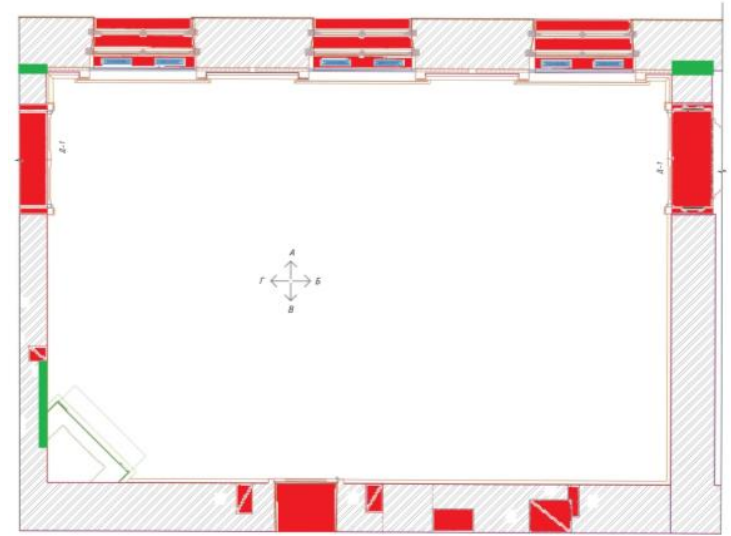

Fig. 10. The drawing showing the walls, smoke and ventilation ducts, door and window openings (indicated in red).

Figure 10-11 shows a horizontal section of the room indicating smoke shafts, ventilation ducts and places for cutting walls for installation of heating pipes (-33\% of the total wall area). In total, ventilation ducts and cutting walls for the heating system - approximately $6 \%$. The drawing does not take into account the weakened masonry of smoke shafts made on clay mortar.

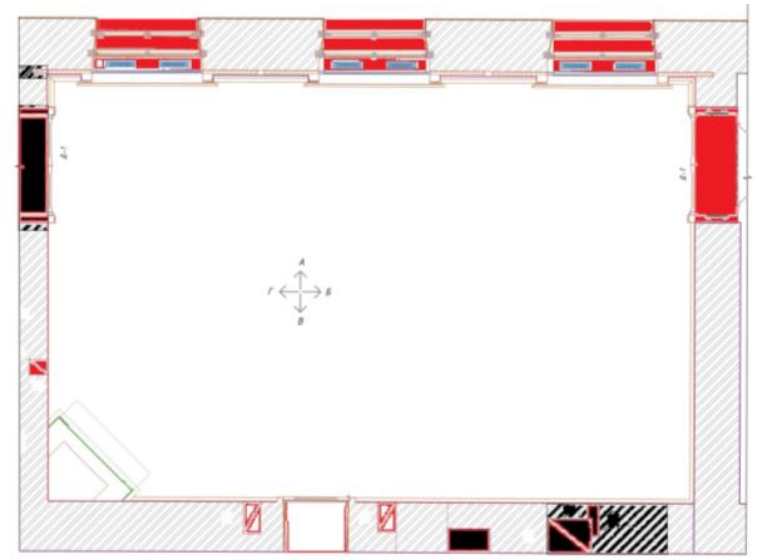

Fig. 11. The volume of re-laid and replenished brickwork during restoration work is shown in black. 
According to the results of restoration work, $0.3 \mathrm{~m}^{3}$ of voids and broken channels were laid in the walls. The walls are completely re-laid with the addition of new material in a volume of $6 \mathrm{~m}^{3}$.

Summing up, it must be said that the restoration architect must understand the design of the monuments and the history of the object's life when conducting the survey and creating the restoration project.

\section{Conclusions}

Summarizing the above, it can be considered that the current community of restoration designers, to a greater extent, does not take into account many factors that affect the integrity and bearing capacity of masonry of historical walls:

1. Channel patterns are not applied to sections (voids in masonry).

2. The calculation of the designer is carried out on a full-body masonry of walls (hence the overstatement of strength characteristics).

3. Kiln masonry is sometimes made not on lime, but on clay - the masonry strength is lower than we expect. The designers also do not take into account the fact that the heating channels are made on clay solution, and not on lime.

4. A poor historical study of the construction of the monuments does not allow an accurate analysis of the state and existence of the monument.

\section{References}

1. Russian State Standard GOST R 55567-2013 Procedure for organizing and conducting engineering and technical research at cultural heritage sites. Monuments of history and culture. General requirements (with Amendment N 1)

2. Russian State Standard GOST R 53778-2010 Buildings and structures. Rules for inspection and monitoring of technical condition

3. Russian State Standard GOST R 55528-2013 Composition and content of scientific and design documentation for the preservation of cultural heritage objects. Monuments of history and culture. General requirements

4. Russian State Standard GOST 5802-86 Building solutions. Test methods

5. Russian State Standard GOST 7564-97 Rolled products. General rules for sampling, choosing blanks and models for mechanical and technological tests

6. Russian State Standard GOST 8462-85 Wall materials. Methods for determining compressive and bending strengths

7. Russian State Standard GOST 22690-88 Concrete. Strength determination by mechanical methods of non-destructive testing

8. Russian State Standard GOST 530-2012 Ceramic brick and stone. General specifications

9. Russian State Standard GOST 8462-85 Wall materials. Methods for determining compressive and bending strengths

10. A.A. Kedrinsky, M.G. Kolotov, B.N. Ometov, A.G. Raskin, Restoration of architectural monuments of Leningrad (p. 496, Stroyizdat, Leningrad, 1989)

11. L.A. Medersky, KGIOP archive, p. 403 (1973)

12. N.V. Zhiteneva, Famous Buildings of St. Petersburg (p. 158, Almaz, St. Petersburg, 1997) 
13. V.I. Andreeva, Relicviya, № 31, 32-40 (2014)

14. V.V. Gerasimov, Proceedings of the International Conference dedicated to the 200th anniversary of the architect Harald Bosse, 359-384, St. Petersburg (2012)

15. V.G. Isachenko, Architects of St. Petersburg of XVIII - XX centuries, 480, Centerpolygraph, St. Petersburg (2010)

16. V.G. Isachenko, Architects of St. Petersburg: XVIII century, Yu.V. Artemyeva, S.A. Prohvatilova (eds), 1021, Lenizdat, St. Petersburg (1997)

17. V.G. Isachenko, Architects of St. Petersburg: XIX - beg. XX century, Yu.V. Artemyeva, S.A. Prohvatilova (eds.), 1070, Lenizdat, St. Petersburg (1998)

18. V.G. Isachenko, Architects of St. Petersburg: XX century, Yu. V. Artemyeva (ed.), 714, Lenizdat, St. Petersburg (2000)

19. Encyclopedia of St. Petersburg http://encspb.ru/object/2855701392?lc=ru

20. A.O. Rotach, Archive of KGIOP. Monument P-59. Report on the state of wall cladding of 1957-1961 